\title{
Hematopoietic Stem Cell Transplantation in Patients with Heterozygous STAT1 Gain-of-Function Mutation
}

\author{
Ayca Kiykim $^{1} \cdot$ Louis Marie Charbonnier $^{2} \cdot$ Arzu Akcay $^{3} \cdot$ Elif Karakoc-Aydiner $^{1} \cdot$ Ahmet Ozen $^{1} \cdot$ Gulyuz Ozturk $^{3}$. \\ Talal A. Chatila ${ }^{2}$ - Safa Baris ${ }^{1}$
}

Received: 20 December 2017 / Accepted: 21 November 2018 / Published online: 13 December 2018

(C) Springer Science+Business Media, LLC, part of Springer Nature 2018

\begin{abstract}
Purpose Human signal transducer and activator of transcription 1 (STAT1) gain-of-function (GOF) mutations present with a broad range of manifestations ranging from chronic mucocutaneous candidiasis and autoimmunity to combined immunodeficiency (CID). So far, there is very limited experience with hematopoietic stem cell transplantation (HSCT) as a therapeutic modality in this disorder. Here, we describe two patients with heterozygous STAT1 GOF mutations mimicking CID who were treated with HSCT.

Methods Data on the HSC sources, conditioning regimen, graft-versus-host disease (GvHD) and antimicrobial prophylaxis, and the post-transplant course including engraftment, GvHD, transplant-related complications, infections, chimerism, and survival were evaluated. Pre- and post-transplant immunological studies included enumeration of circulating interferon gamma (IFN- $\gamma$ )- and interleukin 17 (IL-17)-expressing $\mathrm{CD}^{+} \mathrm{T}$ cells and analysis of IFN- $\beta$-induced STAT1 phosphorylation in patient 1 (P1)'s T cells.

Results P1 was transplanted with cord blood from an HLA-identical sibling, and P2 with bone marrow from a fully matched unrelated donor using a reduced toxicity conditioning regimen. While P1 completely recovered from her disease, P2 suffered from systemic CMV disease and secondary graft failure and died due to severe pulmonary involvement and hemorrhage. The dysregulated IFN- $\gamma$ production, suppressed IL-17 response, and enhanced STAT1 phosphorylation previously found in the CD4 ${ }^{+}$ $\mathrm{T}$ cells of $\mathrm{P} 1$ were normalized following transplantation.

Conclusion HSCT could be an alternative and curative therapeutic option for selected STATl GOF mutant patients with progressive life-threatening disease unresponsive to conventional therapy. Morbidity and mortality-causing complications included secondary graft failure, infections, and bleeding.
\end{abstract}

Keywords STAT1 - gain-of function mutation · mucocutaneous candidiasis · autoimmunity $\cdot$ hematopoietic stem cell transplantation

Ayca Kiykim, Louis Marie Charbonnier, Gulyuz Ozturk, Talal A. Chatila and Safa Baris contributed equally to this work.

Arzu Akcay

arzuakcay@yahoo.com

$\bowtie$ Safa Baris

safabaris@hotmail.com

1 Division of Pediatric Allergy/Immunology, Marmara University, Fevzi Çakmak Mah. No: 41, Pendik, Istanbul, Turkey

2 Division of Immunology, Boston Children's Hospital and Department of Pediatrics, Harvard Medical School, Boston, MA, USA

3 Acibadem Atakent Hospital, Pediatric Bone Marrow Transplantation Unit, Acibadem University, Istanbul, Turkey

\section{Introduction}

Signal transducer and activator of transcription 1 (STAT1) mediates the actions of many cytokines involved in innate and adaptive immune responses to viruses and intracellular bacteria [1]. Autosomal dominant (AD) gain-of-function (GOF) STAT1 mutations are frequently associated with chronic mucocutaneous candidiasis (CMC), immunodeficiency, and autoimmune phenomena, accompanying with exaggerated $\mathrm{T}$ helper cell type $1\left(\mathrm{~T}_{\mathrm{H}} 1\right)$ and defective $\mathrm{T}$ helper cell type $17\left(\mathrm{~T}_{\mathrm{H}} 17\right)$ responses [2-7].

There is ambiguity concerning the optimal management approaches for patients with STATI GOF mutations. The standard of care usually consists of supportive therapy options including antimicrobial prophylaxis, alone or together with 
immunoglobulin replacement therapy, especially for patients who have recurrent respiratory tract infections, with or without antibody deficiency $[7,8]$. In addition, a case report of a patient with a STATI GOF mutation has shown that treatment with granulocyte-colony-stimulating factor (G-CSF) improved the generation of $\mathrm{T}_{\mathrm{H}} 17$ cells and recovery from fungal infections [9]. Oral therapy with ruxolitinib, a Janus kinase $1 / 2$ (JAK1/2) inhibitor that attenuates STAT1 activation by cytokine receptors, was also shown to be a viable alternative in controlling disease complications, including mucocutaneous candidiasis and autoimmunity $[10,11]$. On the other hand, a small number of patients have been treated with hematopoietic stem cell transplantation (HSCT) with mixed outcomes, rendering a recommendation for this therapy inconclusive $[7$, 12-15]. Therefore, the accrual of additional HSCT results on patients with STAT1 GOF mutations would offer valuable information relevant to the management of this disease.

Here, we report the results of HSCT carried out on two previously reported patients with STATI GOF mutations who presented with a severe disease course mimicking combined immune deficiency (CID) [16].

\section{Methods}

Patient Demographics and HSCT Procedure Clinical data on the patients were collected retrospectively. HSCT was applied according to the EBMT/ESID guidelines for HSCT for primary immunodeficiencies. Data collected included HSC sources, details of the conditioning regimen, graft-versus-host disease (GvHD) and antimicrobial prophylaxis, and post-transplant (engraftment, GvHD, transplant-related complications, infections, chimerism, survival) period. Chimerism analysis was assessed starting at the fourth week of transplantation and onward by using polymerase chain reaction (PCR)-based amplification of sort tandem repeat sequences. Neutrophil and platelet recovery were defined according to the EBMT guidelines as the first of the three consecutive days with a neutrophil count $>500 / \mathrm{mm}^{3}$ and an unsupported platelet count $>20.000 /$ $\mathrm{mm}^{3}$, respectively. Viral infections were treated preemptively, considering previous patients' infections. Viral pathogens, including cytomegalovirus (CMV), Epstein Barr virus (EBV), herpes simplex virus (HSV) types 1 and 2, adenovirus, parvovirus, and human herpesvirus 6 (HHV-6), were assessed weekly in the blood by quantitative PCR. CMV disease was defined as CMV infection involving organ tissues. The presence of a CMV infection was ascertained by a positive blood CMV PCR test result. A written informed consent for transplantation was obtained from the parents.

Antibodies and Flow Cytometry Monoclonal antibodies (mAbs) to the following human proteins were used for staining: CD3 (UCHT1), CD4 (RPA-T4), IFN- $\gamma$ (4S.B3), IL-17
(BL168) (Biolegend), phospho (p)-STAT1 (KIKSI0803) (all from eBioscience), and STAT1 (246523; R\&D Systems). Appropriate isotype controls were used in parallel. Peripheral blood mononuclear cells (PBMCs) were incubated with $\mathrm{mAbs}$ against surface markers for $30 \mathrm{~min}$ on ice. Intracellular staining with STAT1 $\mathrm{mAb}$ was performed using an eBioscience fixation/permeabilization kit according to the manufacturer's instructions. For p-STAT1 staining, PBMCs were stimulated for $20 \mathrm{~min}$ with appropriate cytokines in complete medium, fixed with $2 \%$ paraformaldehyde for $20 \mathrm{~min}$ on ice, permeabilized with $90 \%$ methanol for $30 \mathrm{~min}$ on ice, and stained using CD3, CD4, and p-STAT1 mAbs in PBS for $30 \mathrm{~min}$. For cytokine detection, cell suspensions were incubated with phorbol myristate acetate (PMA) (Sigma-Aldrich; $50 \mathrm{ng} / \mathrm{mL}$ ), Ionomycin (Sigma-Aldrich; $500 \mathrm{ng} / \mathrm{mL}$ ), and GolgiPlug ${ }^{\mathrm{TM}}$ (BD Biosciences; according to the manufacturer's instructions) for $4 \mathrm{~h}$ in complete medium before surface staining. Permeabilization and intracellular interferon (IFN)- $\gamma$ and IL-17 staining were carried out using an eBioscience Fixation/Permeabilization kit as described above. Data were collected with an LSRFortessa ${ }^{\mathrm{TM}}$ cytometer (BD Biosciences) and analyzed with the FlowJo software (Tree Star, Inc.).

Statistical Analysis Comparisons between the results on patient and healthy controls were analyzed using the two-way ANOVA with post-test analysis, with $p$ values less than 0.05 considered statistically significant.

\section{Results}

Patient 1 (P1) Patient 1 is a 3-year-old girl who presented soon after birth with recurrent urosepsis and refractory oral candidiasis despite oral fluconazole therapy. The details of the patient's clinical features were previously described, and are summarized in Table 1 [16]. She also suffered from CMV pneumonitis, mycobacterial lung disease, and hepatitis of possible autoimmune etiology. A mutation was found in the DNA binding domain (DBD) of STAT1; c.1154C > T, p.T385M [16]. The patient's T cells exhibited STAT1 hyperphosphorylation in response to treatment with IFN- $\beta$ as compared to $\mathrm{T}$ cells of control subjects. Analysis of her circulating $\mathrm{CD}^{+} \mathrm{T}$ cells revealed increased frequencies of IFN $-\gamma^{+} \mathrm{CD} 4^{+}\left(\mathrm{T}_{\mathrm{H}} 1\right.$ type) $\mathrm{T}$ cells, and decreased frequencies of IL- $17^{+} \mathrm{CD}^{+}{ }^{+} \mathrm{T}_{\mathrm{H}} 17$ type) $\mathrm{T}$ cells, consistent with the effects of the STAT1 GOF mutation of $\mathrm{T}_{\mathrm{H}}$ cell skewing [16].

At age 2 years, and despite medical therapy, she continued to suffer from unrelenting lung infections, giving the impetus for HSCT. She received unmanipulated, CMV seronegative, umbilical cord HSC from a genetically HLA-identical sister who had normal STAT1 gene sequencing. A reduced toxicity conditioning regimen with treosulfan/fludarabine/thymoglobulin (ATG) was applied. She received valganciclovir (CMV blood 
Table 1 The clinical features of the patients before HSCT

\begin{tabular}{|c|c|c|c|c|c|c|}
\hline Patients & Sex & $\begin{array}{l}\text { Age of } \\
\text { onset }\end{array}$ & Mutation and domain & Infections before HSCT & Autoimmunity & $\begin{array}{l}\text { Therapy received } \\
\text { before HSCT }\end{array}$ \\
\hline P1 & Female & 2 months & $\begin{array}{l}\text { c. } 1154 \mathrm{C}>\mathrm{T}, \\
\text { p.T385M (DBD) }\end{array}$ & $\begin{array}{l}\text { CMC } \\
\text { CMV } \\
\text { M. tuberculosis } \\
\text { Pneumonia } \\
\text { Urosepsis }\end{array}$ & $\begin{array}{l}\text { Hepatitis } \\
\text { Hypopigmented skin } \\
\quad \text { lesions (like vitiligo) }\end{array}$ & $\begin{array}{l}\text { Ganciclovir } \\
\text { Valganciclovir } \\
\text { Anti-TB drugs } \\
\text { TMP-SMX } \\
\text { Fluconazole } \\
\text { Voriconazole } \\
\text { CS } \\
\text { IVIG }\end{array}$ \\
\hline $\mathrm{P} 2$ & Male & 4 months & $\begin{array}{l}\text { c. } 971 \mathrm{G}>\mathrm{T} \\
\text { p.C324F (DBD) }\end{array}$ & $\begin{array}{l}\text { CMC } \\
\text { CMV } \\
\text { Pneumonia }\end{array}$ & - & $\begin{array}{l}\text { Ganciclovir } \\
\text { Valganciclovir } \\
\text { TMP-SMX } \\
\text { Fluconazole } \\
\text { Voriconazole } \\
\text { IVIG }\end{array}$ \\
\hline
\end{tabular}

$C M C$ chronic mucocutaneous candidiasis, $C M V$ cytomegalovirus, $C S$ corticosteroid, $T M P-S M X$ trimethoprim-sulfamethoxazole, $I V I G$ intravenous immunoglobulin, $T B$ tuberculosis

${ }^{\text {a }}$ Anti-TB drugs used until HSCT: isoniazid, rifampicin, ethambutol, pyrazinamide, cycloserine, and levofloxacin

PCR was negative at transplantation) and voriconazole prophylaxis in addition to the anti-bacterial (ciprofloxacin) and antimycobacterial therapies (ethambutol, cycloserine, levofloxacin), which was started at 9 months of age. The details of the HSCT procedure are presented in Table 2. The total infused stem cells was $3.4 \times 10^{5} \mathrm{CD} 34^{+}$cells $/ \mathrm{kg}$. Prophylaxis therapy was initiated, consisting of cyclosporine (CsA) and corticosteroid (CS) for GvHD and defibrotide for sinusoidal obstruction syndrome (SOS). Hematological recovery was achieved for granulocytes on day +28 and for platelets on day +41 . Despite oral valganciclovir prophylaxis, she had CMV infection at day +4 , which was controlled with ganciclovir therapy. Screening for other viral agents including EBV, HSV types 1 and 2, adenovirus, parvovirus, and HHV-6 were negative during the follow up.

There were no signs for acute or chronic GvHD, and due to mixed lymphocyte chimerism ( $23 \%$ donor) on day +32 , CsA was stopped on day +40 . At day +83 , she suffered from acute toxic hepatitis that was ascribed to prolonged anti-TB prophylaxis, which resolved after drug discontinuation. Sequential chimeric analyses at days $+90,+153,+190,+270$, and +420 post-transplant showed $80,90,85,82$, and $100 \%$ donor chimerism, respectively. The chimerism increased spontaneously after stopping immunosuppressive drugs without other interventions. At day +720 , the whole blood and lymphocyte (including both $\mathrm{T}$ and $\mathrm{B}$ cells) chimerism levels were $100 \%$ donor cells. Lymphocyte subset analysis at that time revealed the peripheral blood $\mathrm{CD}^{+} \mathrm{T}$ cells at $3190 / \mathrm{mm}^{3}(58 \%)$, $\mathrm{CD}^{+} \mathrm{CD}^{+} \mathrm{T}$ cells at $1815 / \mathrm{mm}^{3}(33 \%), \mathrm{CD}^{+} \mathrm{CD}^{+} \mathrm{T}$ cell at $1265 / \mathrm{mm}^{3}$ (23\%), CD19 $\mathrm{B}$ cells at $1870 / \mathrm{mm}^{3}$ (34\%), and CD16 $6^{+} 56^{+}$NK cells at $330 / \mathrm{mm}^{3}(6 \%)$.

To confirm the resolution of her underlying STAT1 GOF signaling phenotype post -transplantation, we compared the induction of STAT1 phosphorylation in her $\mathrm{CD} 4^{+} \mathrm{T}$ cells obtained pre- and post-transplant in response to treatment with IFN- $\beta$. Analysis revealed that the enhanced STAT1 phosphorylation previously noted upon treatment of her $\mathrm{CD} 4^{+} \mathrm{T}$ cells with IFN- $\beta$ significantly decreased down to normal control levels following transplantation $(p<0.0001$, Fig. 1a, b). Similarly, her dysregulated IFN- $\gamma / \mathrm{IL}-17 \mathrm{CD} 4^{+} / \mathrm{CD}^{+} \mathrm{T}$ cell responses were also normalized (Fig. 2). She is now at 24 months after transplantation with continued $100 \%$ donor chimerism without medication.

Patient 2 (P2) Patient 2 is a 3-year-old male who was originally reported as P2 in our earlier publication [16]. Details of his pretransplant clinical features are presented in Table 1 [16]. Sanger sequencing revealed heterozygous de novo STAT1 missense mutation (c.971G > T; p.C324F) at DBD. At age 2.5 years, and in view of uncontrolled recurrent $\mathrm{CMV}$ disease with severe lung involvement, oral candidiasis resistant to azole treatment, and overall poor quality of life, the patient was transplanted using 10/10 matched unrelated bone marrow donor, who was CMV seronegative. At that time, the patient's blood CMV PCR was negative under valganciclovir therapy. The patient received a reduced toxicity conditioning regimen with treosulfan/ fludarabine/ATG (Table 2). The total transfused stem cells were $6.95 \times 10^{6} \mathrm{CD} 34^{+}$cells $/ \mathrm{kg}$. CsA and mycophenolate mofetil (MMF) were used for GvHD prophylaxis and defibrotide for SOS. G-CSF was used from day +8 until +19 . Hematological recoveries were achieved for granulocytes on day +13 and on day +17 for platelets. The granulocyte numbers remained higher than $1000 / \mathrm{mm}^{3}$ between days +15 and +22 , but they declined to $500 / \mathrm{mm}^{3}$ on day at day +23 . G-CSF therapy was therefore initiated at a frequency of once every 4 days, which helped sustain the granulocyte numbers above $1000 / \mathrm{mm}^{3}$. 
Table 2 The details and outcome of the HSCT procedure

\begin{tabular}{|c|c|c|}
\hline & P1 (3 years/girl) T385M & $\mathrm{P} 2$ (3 years/boy) $\mathrm{C} 324 \mathrm{~F}$ \\
\hline Age at HSCT & 2 years & 2.5 years \\
\hline Source of donor & HLA-identical sister & Match unrelated donor \\
\hline Source of HSC (matching) & UCB $6 / 6$ & Bone marrow $(10 / 10)$ \\
\hline Conditioning & $\begin{array}{l}\text { - Treo } 14 \mathrm{~g} / \mathrm{m}^{2} / \text { day, from }-5 \text { to }-3 \\
\text { - Flu } 40 \mathrm{mg} / \mathrm{m}^{2} / \text { day, from }-5 \text { to }-2 \\
\text { - ATG } 2.5 \mathrm{mg} / \mathrm{kg} / \text { day, from }-9 \text { to }-6\end{array}$ & $\begin{array}{l}\text { - Treo } 14 \mathrm{~g} / \mathrm{m}^{2} / \text { day, from }-5 \text { to }-3 \\
\text { - Flu } 30 \mathrm{mg} / \mathrm{m}^{2} / \text { day, from }-5 \text { to }-2 \\
\text { - ATG } 2.5 \mathrm{mg} / \mathrm{kg} / \text { day, from }-5 \text { to }-2\end{array}$ \\
\hline \multicolumn{3}{|l|}{ Prophylaxis } \\
\hline Anti-viral & Valganciclovir & Valganciclovir \\
\hline Anti-fungal & Voriconazole & Voriconazole \\
\hline Anti-mycobacterial & Ethambutol, cycloserine, levofloxacin & - \\
\hline Anti-bacterial & Ciprofloxacin & Azithromycin, ciprofloxacin \\
\hline Donor CD34+cells $/ \mathrm{kg}$ & $3.4 \times 10^{5}$ & $6.95 \times 10^{6}$ \\
\hline GvHD prophylaxis & $\begin{array}{l}\text { - CsA, days }-1 \text { to }+40 \\
\text { - CS, days } 0 \text { to }+14 \text {; tapered in } 2 \text { weeks } \\
\quad \text { (a total of } 28 \text { days) }\end{array}$ & $\begin{array}{l}\text { - CsA, days }-1 \text { to }+40 \\
\text { - MMF, days }+1 \text { to }+40\left(2 \times 400 \mathrm{mg} / \mathrm{m}^{2}\right)\end{array}$ \\
\hline Myeloid engraftment & Day +28 & Day +13 \\
\hline Platelet engraftment & Day +41 & Day +17 \\
\hline GvHD & No & Grade II skin \\
\hline Transplant-related infections & $\begin{array}{l}\text { CMV infection } \\
\text { Klebsiella pneumonia bacteremia }\end{array}$ & $\begin{array}{l}\text { CMV pneumonia } \\
\text { S. epidermidis bacteremia } \\
\text { Klebsiella pneumonia bacteremia } \\
\text { Acinetobacter pittii (catheter-related infection) }\end{array}$ \\
\hline Outcome & $100 \%$ donor chimerism, alive & $\begin{array}{l}\text { Secondary graft failure, disseminated } \\
\text { CMV disease, deceased }\end{array}$ \\
\hline
\end{tabular}

$U C B$ umbilical cord blood, $B M$ bone marrow, Flu fludarabine, Treo treosulfan, $A T G$ thymoglobulin, $G v H D$ graft-versus-host disease, $C s A$ cyclosporine, $M M F$ mycophenolate mofetil, $C S$ corticosteroid, $C M V$ cytomegalovirus

Despite CMV prophylaxis with valganciclovir, CMV infection was detected on day + 26 (blood CMV PCR 1294 copies/ml) and systemic ganciclovir was initiated in addition to intravenous immunoglobulin therapy. On day +35 , systemic and local methyl prednisolone therapy was initiated in addition to the ongoing CsA and MMF due to the clinically diagnosed grade II acute skin GvHD. The skin lesions were alleviated by day + 39 in response to therapy, and a skin biopsy was not undertaken to confirm the GvHD. Meanwhile, the result of the bone marrow chimerism analysis performed on day +40 showed absence of donor cells. The absent chimerism was thought to reflect a secondary graft failure; consequently, all immune suppressive agents were stopped. His lung infiltrates progressed, and on day +45 , Klebsiella pneumonia was detected in blood culture, while Acinetobacter pittii was cultured from his central catheter, leading to the initiation of broad-spectrum antibiotic therapy. During this period, his absolute lymphocyte and granulocyte numbers were persistently less than 100 and $500 / \mathrm{mm}^{3}$, respectively. Later on, owing to the control of the CMV infection, ganciclovir therapy was switched to valganciclovir on day +53 . However, CMV infection was observed to recur on day + 64, with the virus detected in the blood at 5884 copies $/ \mathrm{ml}$. Accordingly, ganciclovir therapy was started again in an attempt to control the CMV infection. Nevertheless, the patient's clinical condition progressively deteriorated with septicemia, pancytopenia, and severe diffuse interstitial lung involvement associated with an elevated CMV load. Foscarnet and CMV hyper-immune globulin were added to the ganciclovir therapy at day +86 . However, the patient was admitted to the intensive care unit on day +90 and supported by mechanical ventilation. High levels of CMV were detected in the blood, endotracheal aspirates, and urine as 583,580, 3,450,000, and 2170 copies $/ \mathrm{ml}$, respectively. Despite the broad range of antimicrobial coverage, including cidofovir therapy, he developed acute respiratory distress syndrome and pulmonary hemorrhage, which led to his death at day +106 .

\section{Discussion}

In this report, we evaluated the outcome of HSCT in two patients with heterozygous STAT1 mutations in the DBD [16]. HSCT resulted in successful and sustained disease control in one patient (P1), highlighting the decisive role of the hematopoietic cell lineages in disease pathogenesis and manifestations. The fatal outcome due to secondary graft failure in the other 
Fig. 1 Normalization of STAT1 hyperphosphorylation in STATI GOF mutated patient after transplantation. a Pre- and posttransplantation total p-STAT1 expression in $\mathrm{CD}^{+} \mathrm{T}$ cells stimulated with IFN- $\beta(20 \mathrm{ng} / \mathrm{mL})$ by flow cytometry in patient (P1) compared to healthy control. b The dose response curve of STAT1 phosphorylation induced with IFN- $\beta$ in patient and control $\mathrm{CD}^{+}$T cells. $* * * p<0.0001$ by two-way ANOVA. $T x$ transplantation

\section{a}

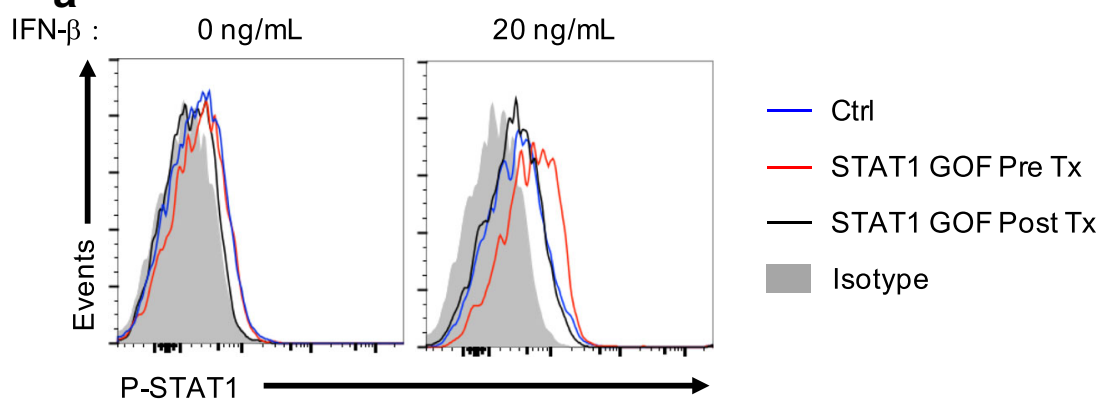

b

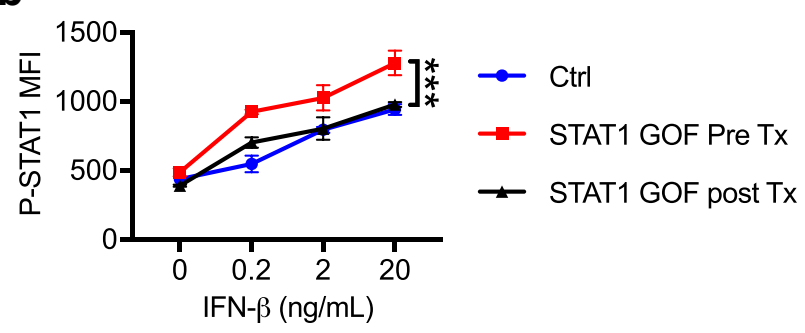

(P2) emphasizes the remaining challenges in optimizing this therapy for high-risk patients with severe disease.

HSCT has been performed in a few STAT1 GOF mutated patients with inconsistent results and high mortality [7, 12-15 and this report]. A comparative analysis of the details of the HSCT procedure is presented in Table 3. In a recent cohort including 15 STAT1 GOF transplanted patients, HSCT was conducted due to severe persistent CMC and bacterial or systemic viral infections, Immune dysregulation-PolyendocrinopathyEnteropathy-X-linked (IPEX)-like symptoms refractory to medical therapy, CID, or hemophagocytic lymphohistiocytosis (HLH) [7, 12, 13, 15]. Interestingly, the majority of transplanted patients had DBD mutations (M390T, N397D, T385M, N397D, S466R, C324F), while the rest had coiled coil domain mutations (D165G, R274W, R274Q, D292E, I294T, H328R), reflecting perhaps a more severe disease course in patients with DBD mutations, for whom HSCT might be considered as an earlier therapeutic option.

A major concern with HSCT in STAT1 mutated patients is the high rates of secondary graft failure, the cause of which is

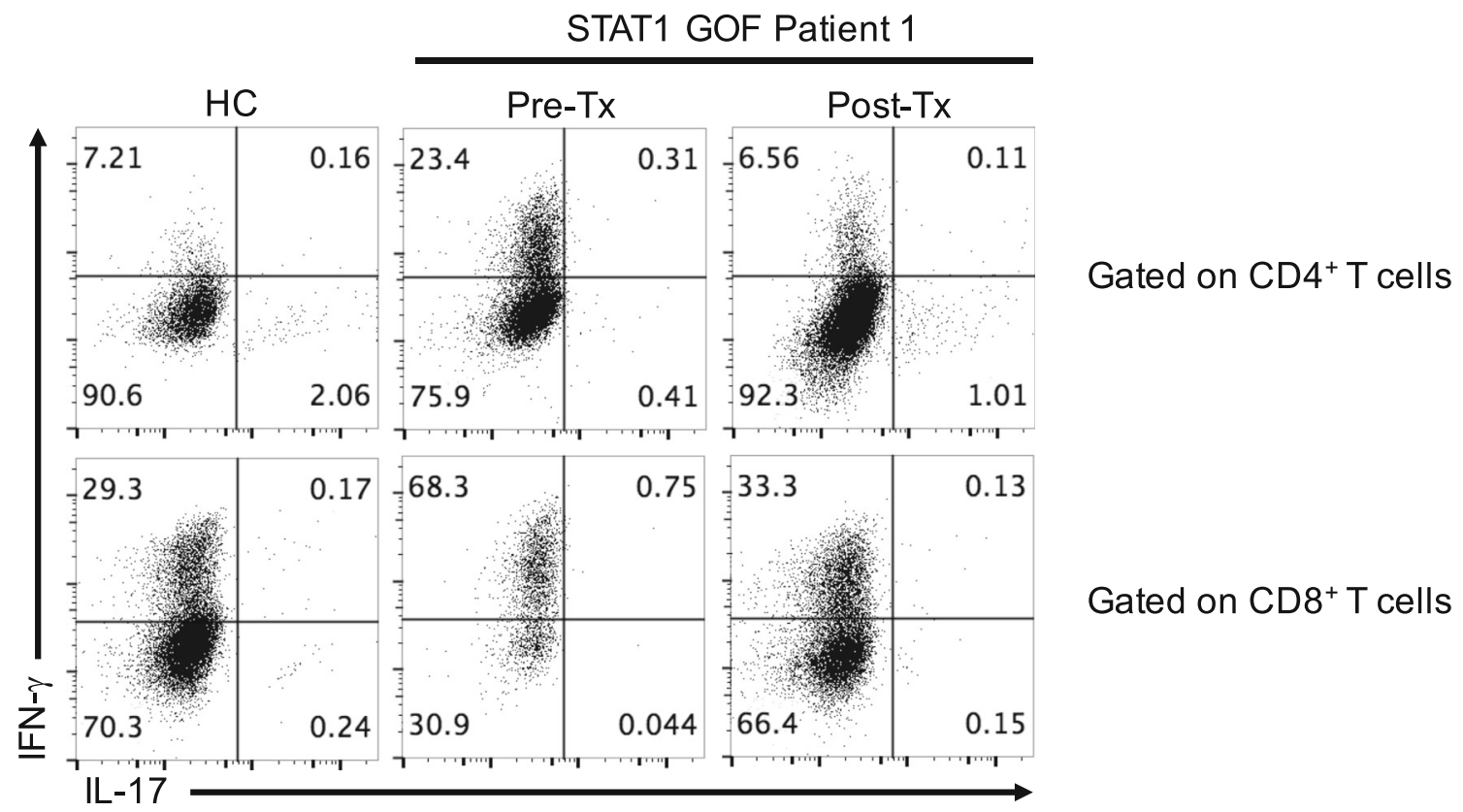

Fig. 2 Normalization of $\mathrm{T}_{\mathrm{H}} 1$ cell skewing and improved $\mathrm{T}_{\mathrm{H}} 17$ cell responses in STAT1 GOF mutated patient following transplantation. Flow cytometric analyses of IL-17 and IFN- $\gamma$ expression in peripheral blood $\mathrm{CD}^{+}$and $\mathrm{CD} 8^{+} \mathrm{T}$ cells of $\mathrm{P} 1$ before and after transplantation as compared to a control subject 


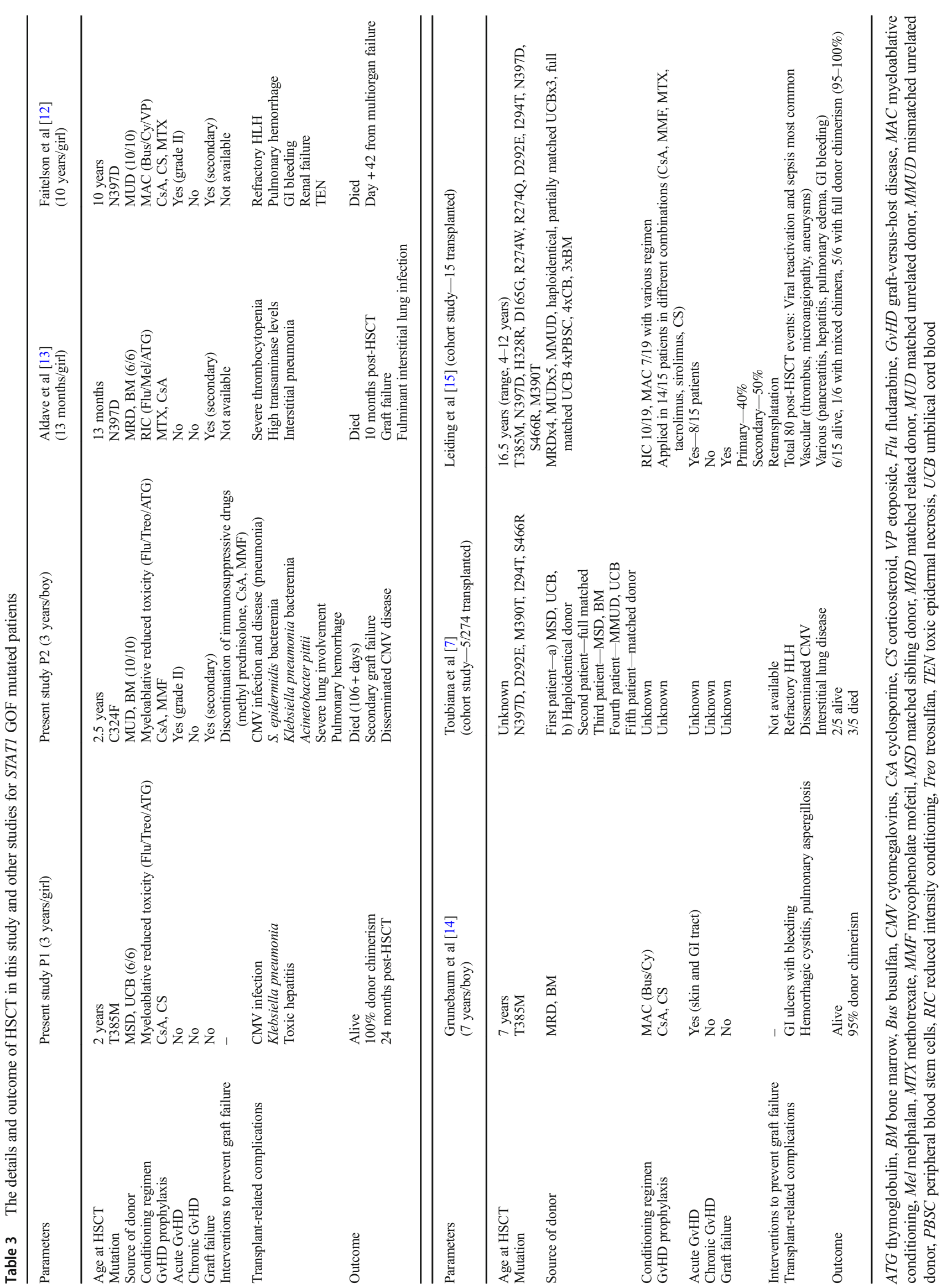


not fully understood [15]. It was not found to be related to genotype, phenotype, conditioning regimen, patient's age, donor type, and HSC source. On the other hand, enhanced interferon signaling in STAT1 GOF might be mechanistically related to the secondary graft failure, but such a link remains to be firmly established [15].

An international STAT1 GOF study group published five transplanted patients with AD STAT1 GOF mutations [7]. Only two of them are currently alive without serious complications. In the Leiding et al. transplantation cohort, 6 patients (40\%) survived [15]. One of the patients who survived had complete secondary graft loss and underwent a second HSCT and then had full immune reconstitution. Another patient had split donor chimerism, while the rest of the patients were reported to have 95-100\% immune reconstitution [15]. Our patient $\mathrm{P} 1$ continues to live with complete disease remission and evidence by in vitro functional analyses of normalized IFN- $\gamma /$ IL-17 responses and STAT1 phosphorylation in T cells post-transplantation.

Despite using HLA-identical donors, the majority of STAT1 GOF mutated patients who received HSCT died due to transplant-related complications [7, 15 and this report]. In the Toubiana et al. STAT1 cohort, the three patients who died posttransplant suffered complications that included CMV infection, diffuse interstitial lung involvement, and uncontrolled HLH [7]. In the Leiding et al. cohort, those patients who manifested a CID phenotype prior to their HSCT experienced increased infections post-transplant [15]. Younger age at the time of transplantation and the use of a reduced intensity regimen were found to be associated with increased overall survival [15]. Our patient P2 and the other reported patients who did not survive after HSCT therapy had serious disease-related morbidities, including severe infections and in some cases HLH prior to transplantation, which could amplify transplant-related complications and foster poor prognosis $[13,15]$. Similar to patient $\mathrm{P} 2$, bleeding complications were also reported in transplanted STAT1 GOF mutated patients $[14,15]$. Hyperactivation of the IFN- $\gamma$ pathway may also be associated with poor engraftment and outcome after transplantation in STATI GOF mutated patients. In this regard, the pre-transplant use of ruxolitinib to suppress hyperactive IFN responses was found to be associated with full immune reconstitution and less post-transplant complications [15].

In our two STAT1 GOF mutated patients, valganciclovir was chosen for CMV prophylaxis due to the frequent virus infection and the need to maintain sustained CMV suppression before transplantation. In recent years, valganciclovir has been used as an effective and safe drug for preemptive therapy in the adult and pediatric populations after allogeneic HSCT $[17,18]$. Previously, we demonstrated that treatment with oral valganciclovir or intravenous ganciclovir alone were equally effective in reducing CMV DNA load in pediatric HSCT patients [17]. Nevertheless, and despite prophylaxis, breakthrough CMV infection was observed in both of our patients, emphasizing the need to aggressively suppress CMV disease in the context of HSCT for this disorder.

Our study has some limitations, which need to be mentioned. Patient P2 likely had engrafted donor cells after transplantation and developed GvHD (albeit not confirmed by a skin biopsy), which was controlled by immunosuppressive therapy. However; we could not ascertain the status of donor chimerism in the early post-transplantation period until day +40 . With the lack of this information, the treatment of the patient's presumptive GvHD with immunosuppressive drugs might have increased the risk of graft rejection. On the other hand, it should be kept in mind that GvHD could itself be a cause of graft rejection. These issues emphasize the need for performing early chimerism studies in patients at high risk of graft rejection, which in the case of low or mix chimerism would allow early interventions such as tempering the use of immunosuppressive drugs and/or infusion of donor lymphocytes or stem cells to stabilize the graft. Finally, using a CMV seronegative donor for patients with active CMV infection could be one of the reasons for the progression of CMV disease, as in the case of patient P2. Therefore, selection of CMV seropositive donors in patients with CMV may result in a better outcome.

In conclusion, HSCT provides an alternative therapeutic option for subjects with STATI GOF mutations who have an unrelenting disease course despite conventional therapy. Close disease monitoring, aggressive treatment of complications, and early donor screening for HSCT should be provided for patients with severe phenotype, especially before development of end organ damage. Furthermore, stabilizing patients before transplantation and anticipating common complications post-transplantation for early intervention (e.g., bleeding and graft failure) may enhance the survival rates.

Acknowledgments This manuscript is dedicated to the memory of Professor Dr. Isil Berat Barlan (1958-2015). This work was supported by the National Institutes of Health (5R01AI065617) to T.A.C and a grant from the Scientific and Technological Research Council of Turkey (1059B191401284) to S.B.

\section{Compliance with Ethical Standards}

Conflict of Interest The authors declare that they have no conflict of interest.

Publisher's Note Springer Nature remains neutral with regard to jurisdictional claims in published maps and institutional affiliations.

\section{References}

1. Casanova JL, Holland SM, Notarangelo LD. Inborn errors of human JAKs and STATs. Immunity. 2012;36(4):515-28.

2. van de Veerdonk FL, Plantinga TS, Hoischen A, Smeekens SP, Joosten LA, Gilissen C, et al. STAT1 mutations in autosomal dominant chronic mucocutaneous candidiasis. N Engl J Med. 2011;365(1):54-61. 
3. Liu L, Okada S, Kong XF, Kreins AY, Cypowyj S, Abhyankar A, et al. Gain-of-function human STAT1 mutations impair IL-17 immunity and underlie chronic mucocutaneous candidiasis. J Exp Med. 2011;208(8):1635-48.

4. Hori T, Ohnishi H, Teramoto T, Tsubouchi K, Naiki T, Hirose Y, et al. Autosomal-dominant chronic mucocutaneous candidiasis with STAT1-mutation can be complicated with chronic active hepatitis and hypothyroidism. J Clin Immunol. 2012;32(6):1213-20.

5. Marodi L, Cypowyj S, Toth B, Chernyshova L, Puel A, Casanova JL. Molecular mechanisms of mucocutaneous immunity against Candida and Staphylococcus species. J Allergy Clin Immunol. 2012;130(5):1019-27.

6. Kagawa R, Fujiki R, Tsumura M, Sakata S, Nishimura S, Itan Y, et al. Alanine-scanning mutagenesis of human signal transducer and activator of transcription 1 to estimate loss- or gain-offunction variants. J Allergy Clin Immunol. 2017;140(1):232-41.

7. Toubiana J, Okada S, Hiller J, Oleastro M, Lagos Gomez M, Aldave Becerra JC, et al. Heterozygous STAT1 gain-of-function mutations underlie an unexpectedly broad clinical phenotype. Blood. 2016;127(25):3154-64.

8. Depner M, Fuchs S, Raabe J, Frede N, Glocker C, Doffinger R, et al. The extended clinical phenotype of 26 patients with chronic mucocutaneous candidiasis due to gain-of-function mutations in STAT1. J Clin Immunol. 2016;36(1):73-84.

9. Wildbaum G, Shahar E, Katz R, Karin N, Etzioni A, Pollack S. Continuous G-CSF therapy for isolated chronic mucocutaneous candidiasis: complete clinical remission with restoration of IL-17 secretion. J Allergy Clin Immunol. 2013;132(3):761-4.

10. Higgins E, Al Shehri T, McAleer MA, Conlon N, Feighery C, Lilic $\mathrm{D}$, et al. Use of ruxolitinib to successfully treat chronic mucocutaneous candidiasis caused by gain-of-function signal transducer and activator of transcription 1 (STAT1) mutation. J Allergy Clin Immunol. 2015;135(2):551-3.
11. Weinacht KG, Charbonnier LM, Alroqi F, Plant A, Qiao Q, Wu H, et al. Ruxolitinib reverses dysregulated $\mathrm{T}$ helper cell responses and controls autoimmunity caused by a novel signal transducer and activator of transcription 1 (STAT1) gain-of-function mutation. J Allergy Clin Immunol. 2017;139:1629-1640.e2.

12. Faitelson Y, Bates A, Shroff M, Grunebaum E, Roifman CM, Naqvi A. A mutation in the STAT1 DNA-binding domain associated with hemophagocytic lymphohistocytosis. LymphoSign J. 2014;1(2): 87-95.

13. Aldave JC, Cachay E, Nunez L, Chunga A, Murillo S, Cypowyj S, et al. A 1-year-old girl with a gain-of-function STAT1 mutation treated with hematopoietic stem cell transplantation. J Clin Immunol. 2013;33(8):1273-5.

14. Grunebaum E, Kim VH, Somers GR, Shammas A, Roifman CM. Bone marrow transplantation for monoallelic signal transducer and activator of transcription 1 deficiency. J Allergy Clin Immunol. 2016;138(2):612-5 e1.

15. Leiding JW, Okada S, Hagin D, Abinun M, Shcherbina A, Balashov DN, et al. Hematopoietic stem cell transplantation in patients with Gain of Function STAT1 Mutation. J Allergy Clin Immunol. 2018;141(2):704-17.

16. Baris S, Alroqi F, Kiykim A, Karakoc-Aydiner E, Ogulur I, Ozen A, et al. Severe early-onset combined immunodeficiency due to heterozygous gain-of-function mutations in STAT1. J Clin Immunol. 2016;36(7):641-8.

17. Atay D, Erbey F, Akcay A, Dag A, Ozturk G. Oral valganciclovir as preemptive therapy for cytomegalovirus reactivation in pediatric hematopoietic stem cell transplant patients. J Pediatr Hematol Oncol. 2015;37(7):543-7.

18. Takenaka K, Eto T, Nagafuji K, Kamezaki K, Matsuo Y, Yoshimoto $\mathrm{G}$, et al. Oral valganciclovir as preemptive therapy is effective for cytomegalovirus infection in allogeneic hematopoietic stem cell transplant recipients. Int J Hematol. 2009;89(2):231-7. 